\title{
Technology and teaching: Avoiding the pitfalls, increasing student engagement, and improving outcomes
}

\author{
Tami L. Thomas , Imelda Reyes, Amy Blumling \\ Nell Hodgson Woodruff School of Nursing, Emory University, Atlanta, Georgia, United States
}

Received: September 30, 2014

Accepted: December 8, 2014 Online Published: December 17, 2014

DOI: $10.5430 /$ jnep.v5n3p33

URL: http://dx.doi.org/10.5430/jnep.v5n3p33

\begin{abstract}
In an ever-changing educational landscape challenged by rapidly evolving technological advances, nursing educators are challenged to incorporate their best teaching approaches in the classroom and beyond to ensure student engagement and best learning outcomes. Innovation is then balanced with student needs and learning styles. As we respond to the demands of an ever changing health care environment and a new generation of nursing students with a variety of learning styles, we focused our efforts to help these students incorporate challenging material and use their critical thinking skills. We also focused on developing their roles as nurse practitioners who utilize the latest evidence based practice. At the same time, we are trying daily to avoid the educational pitfalls of the past, and to transform curriculum to meet the needs of the students and the pediatric population they will serve. Adapting new technologies should be carefully weighed against the traditional methods of lecturing. Increasingly, hybrid courses, a combination of teaching in the digital environment (online) and face-to-face interaction between students and faculty, are proving to be very effective, and the student feedback regarding this teaching method is overwhelmingly positive. In this article, we share some of our best practices to teaching in this hybrid, digital environment.
\end{abstract}

Key Words: Technology, Teaching, Nursing, Students, Hybrid courses

\section{Introduction}

Teaching within a pediatric nurse practitioner (PNP) curriculum presents challenges of delivering large amounts of content in a format that works with different learning styles and varying backgrounds of nursing knowledge and experience. This challenge is coupled with providing care to a vulnerable population with specialized healthcare. Genetics is especially challenging as the content is not taught like the standard hands on physical assessment, diagnostic reasoning, and prescriptive case studies scenarios used in many programs. ${ }^{[1]}$ Being familiar with the expectations of a current generation of students and applying new teaching tech- niques, like flipping the classroom, present challenges not only on how to deliver content in a timely manner, but also integration of content and application by the student in the clinical setting.

There are many misconceptions regarding hybrid education, especially components that are considered part of the digital environment or online learning. Many of these criticisms include: online courses require less work, there is no meaningful interaction, the quality of learning is not comparable to face-to-face lectures, online components are simply busy work, and learning is delayed and/or completely asynchronous. But Pappas-Rogich and Gehrling ${ }^{[2]}$ discuss the

\footnotetext{
* Correspondence: Tami L. Thomas; Email: surfer1958thomas@ gmail.com; Address: Nell Hodgson Woodruff School of Nursing, Emory University, 1520 Clifton Road NE, \#256, Atlanta, Georgia, United States.
} 
rigor of online education with the implementation of external and internal controls, which dismiss the notions that hybrid environments are only for younger students and that many faculty use technology for technology's sake.

\section{Background}

Nursing education, in particular advanced practice nursing education, is changing in terms of how information is best presented and how students learn. Educators continue to learn and evaluate innovative methods in our approaches to teaching as part of our responses to student feedback and faculty satisfaction with the delivery of specific graduate classes. Ironside ${ }^{[3]}$ argues that disciplines within biomedical science and nursing must push past the era of rote memorization to better prepare nurses for nursing practice in this current decade. We have found, just as research purports, that younger generations of students want information at a faster pace and are more comfortable with technology. ${ }^{[4,5]}$ Additional research data supports the use of new pedagogies $^{[3]}$ and the use of unfolding case studies to bring clinical application opportunities to new material. ${ }^{[6,7]}$ Recognizing education over the last 20 years has evolved from chalkboards and discussions or overhead projectors, to the overuse of tools such as PowerPoint, we, as faculty, are constantly trialing new technologies and education strategies to better engage the student. This process challenges our view as educators about how to best present the concepts and learning objectives in a way that moves us along the continuum of Bloom's taxonomy from knowledge to the actual application and synthesis of information or new way of thinking. ${ }^{[8]}$

When presenting difficult or new content such as genetics, every student starts with a different understanding depending on his or her undergraduate background. Some students take an undergraduate genetics course, while others are exposed to some content through their basic science classes. Maradiegue, Edwards ${ }^{[9]}$ found that many advance practice nursing (APRN) students perceived having minimal knowledge of topics like genetics. ${ }^{[9]}$ At the graduate level, we must assess the exposure of each student as we develop learning methodologies to keep students engaged and prepare them to participate, whether in a synchronous or asynchronous hybrid environment, with challenging content such as genetics. ${ }^{[9]}$ They also summarized the issue best by explaining that the topic of genetics touches many aspects of the care with patients, from physical assessments, diagnostic issues, and assignments of best treatment modalities to integrating content on genetics. ${ }^{[9]}$ It is crucial as nurse practitioner students to learn history-taking and physical assessment of patients during regularly scheduled health maintenance visits or early periodic screening, diagnosis, and treatment (EPSDT) visits.

Well-child visits for pediatric patients encompass a multidimensional approach with the integration of many components, including general development, psychosocial factors, and overall well-being of the child. As we prepare each graduate student to take health histories, the patient's family history and genetic factors influence the student's approach to issues such as counseling on individualized health care plans, understanding the underlying genetic causes, and applying this information. We use the American Nurses Association Essential Genetics and Genomic Competencies for Nurses with Graduate Degrees as a guide in preparing these hybrid courses. ${ }^{[10]}$ These essentials outline the competencies for graduate nursing students under the major categories of risk assessment/interpretation; genetic education/counseling/testing/results; clinical management; ethical/legal/social implications; professional role; leadership and research. These important components are similar, if not the same, to the advanced practice nursing required by the pediatric nurse practitioner at an average well-child visit.

The Social Networking Theory provides the insight and genesis for discussing effective and relevant multi-method approaches to deliver content on genetics to the next generation of graduate students (see Figure 1). The social structure of the student cohort and the arrangement of how information is presented and how discussions ensue relate to how the students access the necessary resources. ${ }^{[11]}$ The newer generations of students have been exposed to various types of technology with social media and thrive in an educational environment that incorporates this technology.

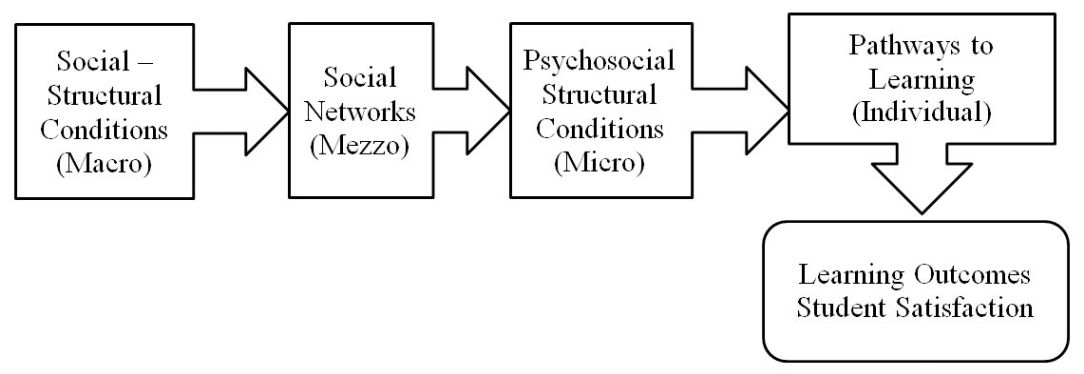

Figure 1: Adapted social networking theory 
In addition, we use the determinants from the technology acceptance model depicted in Figure 2 to evaluate the new strategies of teaching that we have implemented. Within our nursing curriculum, we evaluated the ease of use for tech- nology from the APRN student nurse perspective and how the cohort then developed their attitudes to the new way of learning and evaluated their behavior outcomes and gathered information on how they used the new tools.

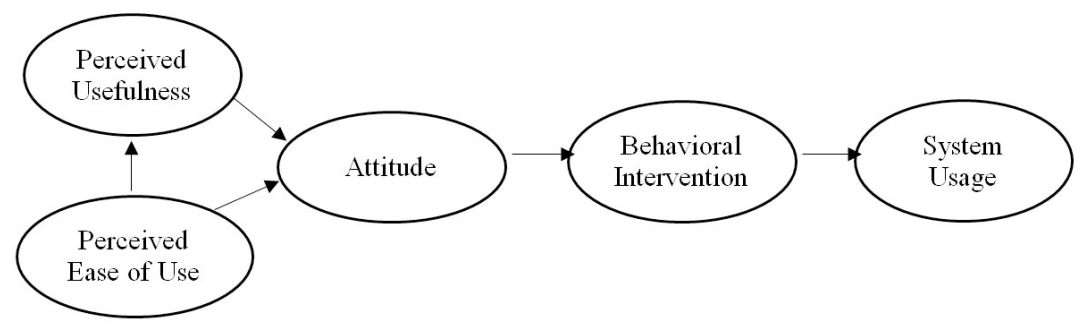

Figure 2: Technology acceptance model

Technologies deployed in an educational setting must be intuitive and add value, and according to the technology acceptance model, have ease of use. ${ }^{[12]}$ Implementing a pedagogical shift from traditional learning to a multi-method approach, including case study approaches, the use of new information technology, and interactive classroom formats set the stage for the formative discussion around best practices and exploration of genetics in pediatrics. McGowan, Wasko $^{[13]}$ found that physicians were willing to use social media more frequently if they found it to be useful and if they could get past the initial adoption and a period of usage phase, despite the fact that perceived barriers were initially high.

\section{Concept-based presentations}

The increased awareness of chronic conditions and silent conditions that require diagnosis via genetic testing can prove to be challenging for the novice pediatric nurse practitioner. Just as McGowan, Wasko ${ }^{[13]}$ found that after the initial adoption period and comfort with use, physicians used more social media, this could also be true within nursing education. Once APRN nursing students are acclimated to the hybrid method of learning and adapt to a new way of learning, the new method could be just as beneficial. Nursing education both at the baccalaureate and graduate level is under pressure to ensure that nursing professionals have the knowledge and skills to meet the health demands of society. Giddens and Brady ${ }^{[14]}$ discuss the frustration from the level of the student in terms of the overwhelming amount of information and memorization required in nursing school. Nursing faculty must resist the temptation to use the digital environment as an automatic data dump via lecture and doing summative evaluations via exams.

Multiple teaching methodologies are needed to ensure students' learning styles are addressed and content is clarified. Distler ${ }^{[15]}$ presents problem-based learning (PBL) as a method to challenge the traditional lecture-test model. Teaching is more dynamic when we allow ourselves as educators to be open to surprises. ${ }^{[16]}$ When the answer is not easily identified by the student, it gives the individual a sense of uncertainty which can mimic the clinical scenarios often presented in primary care. ${ }^{[17]}$ But if nursing faculty prepare students with resources found in the digital environment and use approaches that incorporate the digital environment with the tools to know where to seek information, when to consult properly, and how to interpret basic results, students can develop into better advanced practice nurses.

\section{Methods}

Using quality improvement principles, we challenged the coursework of the pediatric nurse practitioner curriculum and critically reviewed the content covered in the various courses. Reviewing the literature by Diekelmann and Lampe, ${ }^{[8]}$ we critically appraised the content and searched for new strategies for teaching the material. The challenges of teaching in 2013-2014 include engaging students prior to class, so that when a face-to-face seminar or class is held and case studies are presented, students actively problemsolve and integrate information. Offering content in the digital environment online through brief 10-12 minute video and readings gives graduate students the opportunity to process information at their own pace. Students can review and ask questions to clarify content prior to class. This prepares students with the basic information needed prior to class and leads to more challenging content and more complex integration of information with an opportunity to critically think and practice through a scenario prior to a real life clinical situation. Moving content online that requires minimal face-to-face interaction for the acquisitions of knowledge is where we can best apply this approach.

As nurse educators, we cannot assume that the linear ways of teaching are always grasped by students or that students have been exposed to the content in prior classes or programs. ${ }^{[3]}$ Students were presented with study guides or objectives with key questions to answer prior to class. Having notes with key concepts outlined, but not necessarily defined, also helped guide their studies and priorities. Hav- 
ing a variety of exercises where the students present information or use different mediums such as VoiceThread also challenges their understanding of content.

Different technologies were employed throughout the semester including videos created with ScreenChomp and Screencast-o-matic to summarize readings with visuals to explain basic concepts and to allow more time in class for the review of case studies. The intent was to pull the information together using both histories and physical exam findings to develop appropriate differential diagnoses. During the class time, students could use other technologies, such as smart phones or response-ware, to answer questions during the presentation to gauge current knowledge and learning. Given that the real clinical environment encourages the use of evidence-based practice, we encouraged the students to use online tools such as Epocrates ${ }^{\mathrm{TM}}$ on smart phones or other online resources, such as healthcare apps.

One exercise used in class was to have the students develop case studies in the moment and to present the information to fellow students. This exercise was considered a summative evaluation tool, as they used the readings and materials to create a realistic patient with an appropriate chief complaint, history of present illness, review of systems, and physical exam. The student's colleagues were then able to develop differential diagnoses with pertinent positives and negatives included, and if correct, the presenter could continue with management plans and the necessary education for the particular condition. The students found the exercise difficult and challenging, but did reflect that it simulated the clinical situation in that they would be presented a patient and have to formulate an idea within 15 minutes to present to their preceptor. The challenge of presenting a concise case with fellow peers asking questions was a new experience.

Whether the class consisted of 15 or 75 students, the shift to more case studies worked well in the classroom. Some exercises were more of a "pair and share" approach, while others were done in small, pre-assigned groups. During the semester, the class still consisted of quizzes and exams to have a more formal evaluation of knowledge, but they were all executed through Blackboard, the learning content management system, to allow for a mock certification feel. In contrast to the approach taken by Distler, ${ }^{[15]}$ we felt that we needed a quantitative approach to assign and evaluate grades for the class.

\section{An evaluation of the innovations in the words of stu- dents}

This past semester, overall student comments were positive, and pediatric nurse practitioner students noted that incorporating several different approaches to engage them and encourage learning were helpful. The format of the exams and summative evaluations also changed from what students had been accustomed to taking. Similar to what Ironside ${ }^{[3]}$ found, the majority of the questions from exams came from the realm of knowledge and fewer were higher level evaluation or analysis level. At first, students were discouraged and expressed discomfort from the lack of materials that would guide their studying, such as having a PowerPoint presentation with clearly defined objectives with information clearly arranged for exam purposes. In addition, case study presentations using Adobe connect were used to work through clinical scenarios. Feedback from the students included that the environment felt safer because they could use any resource available while chatting online. Exam formats were also changed and included items focused on higher cognitive levels of the material. The overall student and faculty sentiment was that the increased use of case studies in class was reflected in the exam formats and was helpful. While change in curriculum and content was challenging, we continue to have success with students passing the initial certification exam for pediatric nurse practitioners through the Pediatric Nurse Certification Board (PNCB) and also positive evaluations/reviews by students.

As the year has progressed, we continue to evaluate the teaching pedagogies to best meet the needs of students in terms of specialty content, like genetics, which is essential in the care of children. Finding balance in terms of assuming case studies or problem-based learning is the best approach for different material. Listening and continuing to capture student evaluations also assist in evaluating whether our presumptions of the students' need for more technological approaches to teaching met their learning needs.

\section{Discussion and recommendations}

\subsection{Avoidance of pitfalls when teaching with tech- nology}

Creating the best hybrid learning environment means avoiding three major pitfalls. The first is content dump, or using the learning management system (Blackboard, etc.) as a storage place for information. Students frequently will not engage when a learning management system site is used as a resource only. When this occurs, the students do not have the ability to exchange ideas with each other or nursing faculty, which inevitably leads to the second pitfall to avoid one-way communication.

There are numerous student reports, including poor course evaluations, citing long, arduous voice-over PowerPoints and lengthy discussion boards, that added little to no value to graduate student learning and felt more like "busy work". In this model of teaching, students are in a position to either accept information or listen to information without giving their own feedback. This creates an environment where interactive learning, that promotes critical thinking and clinical decision-making, would rarely occur in a real life situation. We recommend faculty avoid these approaches, and instead, institute synchronous online chats, adobe connect 
sessions, and others to help provide an interactive learning environment.

Finally, we encourage nursing faculty to consider a reduced class size when implementing hybrid course work, or when there are large student to faculty ratios. Ideally, breaking students into study groups of 6 to 8 encourages interaction with each other, and allows them to work on joint or team projects that correspond with course objectives. Reducing interaction with faculty by increasing student enrollment with minimal interaction from faculty can create an environment of frustration and poor outcomes.

\subsection{Best practices}

To avoid these pitfalls, the authors encourage faculty to use student feedback, observe student interaction, and employ innovation as lynchpins to course development. First, use student feedback as a guide when piloting new technology in the digital environment. Using the best research findings on teaching and online assessments, we pilot new innovations, like avatar simulations, prior to making them a mandated requirement. In addition, we try to frame content into small components and seek the advice of a Master's prepared Instructional Designer when helping to shape course content. Finally, base your decisions to infuse technology on adapted behavior or learning theories.

Some educators, such as Huckstadt and Hayes, ${ }^{[17]}$ discuss that students tended to favorably review online classes and that the use of online case studies was seen as helpful. However, it is important to maintain careful use of assessment and measurement tools to ensure mastery of the content. ${ }^{[2]}$ Content on specialty topics like genetics can be challenging for nursing students. The next generation of graduate students will continue to demand innovative delivery of content, just as the current generation does, but at a faster pace. As more tools and knowledge regarding nursing pedagogies emerge, the constant need for rapid cycle change will prove to be essential in meeting the needs of students and staying current with the demands of content required at the APRN level. Pappas-Rogich and Gehrling ${ }^{[2]}$ discuss the use of Quality Matters to evaluate the quality of online courses using very specific measures and rubrics.

The final best practice is to implement a formal evaluation process of online materials. We use student feedback and assessments prior to courses, during courses, and after courses. The feedback we receive is then discussed at meetings, where, as a group, we reflect on the student feedback and the needs of students, and then challenge ourselves to create new ways to present concepts in pediatrics, including methods such as narrative pedagogy. ${ }^{[18]}$

\section{Conclusions}

Educating nurses will continue to be a challenge for faculty. When we, as nursing faculty, embrace change and move forward, great personal growth can occur for both the faculty and students. Collecting data and measuring outcomes is an essential to the adaptive nature of our healthcare environment, and requires constant evaluation of how students are reacting to the fast changing curriculum and integration of various teaching methodologies. The most disconcerting issue encountered by our team of nurse educators and faculty while exploring and testing new approaches was the vulnerability we felt as the expected authority in issues related to pediatric care. As nursing faculty, you cannot always anticipate the questions or direction that conversations can take, so being prepared for not knowing all of the answers can be difficult. However, this acceptance and preparation lends itself well to showcasing the need to be fluid, looking for the best answer, and using technology to provide the best evidenced based practice examples.

\section{Conflicts of Interest Disclosure}

The author declares that there is no conflict of interest statement.

\section{References}

[1] Maradiegue AH, Edwards QT, Seibert D. 5-years later - have faculty integrated medical genetics into nurse practitioner curriculum? Int J Nurs Educ Scholarsh. 2013; 10(1): 245-54. PMid:24176964 http://dx.doi .org/10.1515/ijnes-2012-0007

[2] Pappas-Rogich M, Gehrling KR. Assessing and Maintaining Quality and Rigor in an Online DNP Program. Nurse educator. 2013; 38(6): 256-60. PMid:24157674 http://dx.doi.org/10.1097/0 1. NNE.0000435268.38365.11

[3] Ironside PM. Teaching thinking and reaching the limits of memorization: enacting new pedagogies. Journal of Nursing Education. 2005; 44(10): 441-9. PMid:16268040

[4] Broussard BB. To click or not to click: learning to teach to the microwave generation. Nurse Education in Practice. 2012; 12:
3-5. PMid:21470911 http://dx.doi.org/10.1016/j.nepr.20 11.03 .013

[5] Revell SM, McCurry MK. Engaging millennial learners: Effectiveness of personal response system technology with nursing students in small and large classrooms. Journal of Nursing Education. 2010; 49(5): 272-5. PMid:20055325 http://dx.doi.org/10.3928/0 1484834-20091217-07

[6] Day L. Using unfolding case studies in a subject-centered classroom. Journal of Nursing Education. 2011; 50(8): 447-52. PMid:21598861 http://dx.doi.org/10.3928/01484834-201 10517-03

[7] Bennett C, Kennedy S, Donato AS. Preparing NPs for primary care: unraveling complexity with unfolding cases. The Journal of nursing education. 2011; 50(6): 328-31. PMid:21366165 http: //dx.doi.org/10.3928/01484834-20110228-05 
[8] Diekelmann N, Lampe S. Student-centered pedagogies: co-creating compelling experiences using the new pedagogies. Journal of Nursing Education. 2004; 43(6): 245-7. PMid:15230302

[9] Maradiegue A, Edwards QT, Seibert D, Macri C, Sitzer L. Knowledge, perceptions, and attitudes of advanced practice nursing students regarding medical genetics. J Am Acad Nurse Pract. 2005; 17(11): 472-9. PMid:16248880 http://dx.doi.org/10.1111/j $.1745-7599.2005 .00076 . \mathrm{x}$

[10] Greco KE, Tinley S Fau - Seibert D, Seibert D. Development of the essential genetic and genomic competencies for nurses with graduate degrees. 2011: 1-24.

[11] Berkman LF, Glass T Fau - Brissette I, Brissette I Fau - Seeman TE, Seeman TE. From social integration to health: Durkheim in the new millennium. Social Science \& Medicine. 2000; 51(6): 843-57. http://dx.doi .org/10.1016/S0277-9536(00)00065-4

[12] Cheung R, Vogel D. Predicting user acceptance of collaborative technologies: An extension of the technology acceptance model for e-learning. Computers \& Education. 2013; 63: 160-75. http: //dx.doi.org/10.1016/j. compedu.2012.12.003

[13] McGowan BS, Wasko M, Vartabedian BS, Miller RS, Freiherr DD, Abdolrasulnia M. Understanding the factors that influence the adoption and meaningful use of social media by physicians to share med- ical information. Journal of medical Internet research. 2012; 14(5). PMid:23006336 http://dx.doi.org/10.2196/jmir. 2138

[14] Giddens JF, Brady DP. Rescuing nursing education from content saturation: the case for a concept-based curriculum. Journal of Nursing Education. 2007; 46(2): 65-9. PMid:17315564

[15] Distler JW. Critical thinking and clinical competence: Results of the implementation of student-centered teaching strategies in an advanced practice nurse curriculum. Nurse Education in Practice. 2007; 7(1): 53-9. PMid:17689424 http://dx.doi.org/10.1016 /j.nepr.2006.08.003

[16] Mitchell GJ, Jonas-Simpson CM, Cross N. Innovating nursing education: interrelating narrative, conceptual learning, reflection, and complexity science. Journal of Nursing Education and Practice. 2013; 3(4): 30-39. http://dx.doi.org/10.5430/jnep.v3n4 p30

[17] Huckstadt A, Hayes K. Evaluation of interactive online courses for advanced practice nurses. Journal of the American Academy of Nurse Practitioners. 2005; 17(3): 85-9. PMid:15748220 http: //dx.doi.org/10.1111/j.1041-2972.2005.0015.x

[18] Diekelmann N, Smythe E. Covering content and the additive curriculum: how can I use my time with students to best help them learn what they need to know? Journal of Nursing Education. 2004; 43(8): 341-4. PMid:15344369 